\title{
Process of implementing collaborative care and its impacts on the provision of care and rehabilitation services to patients with a moderate or severe traumatic brain injury
}

\author{
This article was published in the following Dove Press journal: \\ Journal of Multidisciplinary Healthcare \\ 28 July 2014 \\ Number of times this article has been viewed
}

\section{Lise R Talbot ${ }^{1,2}$ \\ Annie Lévesque' \\ Josée Trottier'}

'School of Nursing Sciences, Faculty of Medicine and Health Sciences, University of Sherbrooke, 'Étienne-Le Bel Clinical Research Centre and the Research Centre on Aging, Sherbrooke, QC, Canada
Correspondence: Lise R Talbot School of Nursing Sciences, Faculty of Medicine and Health Sciences, University of Sherbrooke,

12e Avenue Nord, Sherbrooke,

QC JIH 5N4, Canada

Tel + I 8195645352

$\mathrm{Fax}+\mathrm{I} 8198206816$

Email lise.talbot@usherbrooke.ca
Objective: The introduction of new services in a rehabilitation center is a unique opportunity to introduce a new model of care and services between two institutions. A hospital and a rehabilitation center experienced a clinical management model inspired by an American approach - collaborative care. The purpose of this study was to describe the implementation of this approach and to provide a perception of the quality of care and services provided to patients with moderate or severe traumatic brain injury and to their caregivers.

Materials and methods: In this qualitative study, individual semistructured interviews were conducted with patients and their caregivers in the hospital and rehabilitation center where the patients were treated. Individual semistructured interviews were conducted with administrators, and two focus groups were held with clinicians before and after the implementation.

Results and conclusion: Ten days' waiting time were saved with the collaborative approach. Implementing the collaborative care approach has been found to have several benefits, including improved communication, coordination of services between institutions, and better preparation, awareness, and involvement of patients and their families. Administrators, clinicians, patients, and caregivers expressed their opinions on the organization of care and services, the needs and expectations of patients and their caregivers, their participation in terms of roles and responsibilities, their perception of continuity of care, their satisfaction with the care process, and their suggestions for improvements.

Keywords: traumatic brain injury, collaborative care, rehabilitation, quality of care

\section{Introduction}

Rehabilitation services and professional resources are heavily mobilized by patients with a traumatic brain injury (PTBI). According to a report on severe trauma in Canada, in 2010-2011 there were 15,190 people with serious brain injuries, of which $77 \%$ were due to an accidental fall or a collision involving a motor vehicle. ${ }^{1}$ According to data on the website of the Regroupement des Associations de Personnes Traumatisées Craniocérébrales du Québec, each year some 13,000 people suffer a TBI in Québec alone. ${ }^{2}$ Of this number, nearly 3,000 require hospitalization, with an average hospital stay of 16 days. ${ }^{1,2}$ As reported by McGarry et al, the cost of such hospitalization is high, estimated at US\$8,189 for 6.7 days in hospital for a moderate TBI and $\$ 16,788$ for 10.2 days for a severe TBI. ${ }^{3}$ These data do not include posthospital rehabilitation, which can average 23 days at a cost of around $\$ 46,000$. Brain-injury cases put a high demand on professional resources, hospitals, and rehabilitation services. 
Recently, a rehabilitation center (RC) and a university hospital center (UHC) set out to improve quality of care and services provided in trauma units. The two institutions found that different factors were compromising the quality and efficiency of care delivery. For example, each facility operated independently, resulting in a fragmentation of services and patients' needs that had a direct impact on the rehabilitation process. Though each institution was expected to provide a continuum of care and services, both observed that they were unable to meet the needs of their patients in a timely fashion. Because the health care system is organized in silos, the lack of coordination in service provision had a direct impact on PTBI. ${ }^{4}$ With emergency departments overloaded, PTBI occupy hospital beds (at an average cost of $\$ 1,000$ per day) while waiting for a place in a rehabilitation unit.

Until recently, the UHC and RC had sought solutions to the accessibility problems encountered in the traditional approach by rethinking separate components of their respective organizations. The shortcomings of the traditional approach primarily involved accessibility, care continuity, and communication within and between institutions. ${ }^{5}$ Recently, the creation of an intensive functional rehabilitation unit and a residential rehabilitation resource at the RC made it necessary to work within an integrated care and services network for PTBI. ${ }^{6}$ The purpose of working in a network was to facilitate the patient's journey through the rehabilitation process, providing continuity of care with no duplication and no repetition. The introduction of new services provided an excellent opportunity to test a new model of organizing care and services, a model based on a US approach called collaborative care (CC). ${ }^{7}$

The CC approach is defined as the "coordinated application of a process of clinical management, centered on the quality of clinical results, assessed by the comprehensiveness and the particularity of the people living the experience of health, in a context of interdisciplinary and interprofessional collaboration". ${ }^{7}$ It involves multiple organizations and partners, and attempts to coordinate all systems related to a given client's care episode, while eliminating any repetitive, redundant, expensive, contradictory, or inadequate measures. Focused more on the client and caregiver, the approach facilitates collaborative work between all of the various partners involved. Clinicians work together to ensure that clients and caregivers are included in decision making, and to maintain the continuity of care and services between different partners and institutions. These aims require recognition of the competence of each professional and partners involved, which in turn develops collaboration, cohesion, alliances, and mutual assistance between everyone providing care and services. Lastly, the CC approach is an innovative management model that allows the quality of care to be measured, taking into account the close connection between on the one hand organizational structure and the communication process and on the other hand outcomes. ${ }^{8}$ The $\mathrm{CC}$ approach was implemented in both facilities in 2008 for patients admitted with a moderate or severe TBI (Glasgow Coma Scale score ranging from 3 to 12).

The main objective of this study was to describe whether applying the CC approach yielded good quality care and services provided to PTBI and their caregivers from the hospital to the rehabilitation center, as perceived by the hospital administrators, clinicians, patients themselves, and their caregivers.

\section{Materials and methods Design}

To meet the research objective, a descriptive research strategy was used. Focus-group discussions, semistructured interviews, and inductive qualitative research tools efficient for obtaining data in new or ill-defined research fields were used to survey the four groups of stakeholders: administrators, clinicians, patients, and caregivers. ${ }^{9}$

The project was approved by the UHC's Health Research Ethics Committee and the RC's Research Ethics Committee. Prior to any participant's involvement, the research team explained the aims and procedures involved in the study, and participants agreed to participate by signing a consent form.

At baseline, the two institutions involved had a service relationship that referred to working in silos. The acute care setting was referring the PTBI to the rehabilitation setting when the medical condition was considered stable by physicians. At that moment, if a bed was available in the rehabilitation setting, then the transfer took place. Communication was limited to paper between the liaison nurses. Families were not always involved in the process, nor were patients included in the care plan discussion having the patient or the caregiver as a decision maker.

\section{Participants and recruitment}

Four groups of stakeholders were defined and recruited using a nonprobabilistic sampling strategy. Convenience sampling was used to recruit administrators and clinicians from both the UHC and the RC to populate the first and second groups, respectively. All administrators and clinicians had to be involved with the target PTBI and represent different disciplines or professions. 
PTBI recruitment was accomplished with the help of the UHC clinical coordinator and the clinical trauma nurse. They were asked to refer to us, after admission to intensive care, any patients with moderate or severe TBI whose rehabilitation was to take place at the UHC and the RC. On receiving a referral, the research assistant met the patient and caregiver to present the research project, obtain their consent, and schedule the first interview. Purposive sampling was used to generate the third group, which consisted of patients over 18 years of age who had suffered a moderate or severe TBI and had agreed to participate. These patients received care and services at the UHC, followed by inpatient or outpatient services from the RC. The fourth group consisted of these patients' caregivers. All participants in both these groups had to be able to speak and understand French or English and live within a $100 \mathrm{~km}$ radius of the $\mathrm{UHC}$ or RC.

\section{Data collection}

Guides for the semistructured interviews and focus groups, constructed following Morgan and Krueger's methodology, were used for collecting data from the four groups. ${ }^{9}$ All questions pertained to study objectives by addressing the quality of care and services provided and the level of satisfaction with the CC approach, specifically the organization of care in the context of post-PTBI rehabilitation, the needs and expectations of all stakeholders (administrators, clinicians, patients, caregivers), the participation of these stakeholders in terms of involvement and responsibilities, the perception of continuity of care, and the satisfaction level of clinicians and administrators regarding the care process before and after implementation of CC. The same questions were asked of all stakeholders.

Two semistructured interviews and two focus groups were conducted with the administrators and clinicians from $\mathrm{UHC}$ and RC, respectively. Each pair of interviews and focus groups was separated by an interval of 1 year. Individual semistructured interviews of about 45 minutes were conducted with the patients and their caregivers. The interviews took place at two points: while patients were hospitalized at the UHC and after their return home, 1 month after leaving the RC's rehabilitation unit. All discussions were recorded on audiotape and transcribed verbatim for coding and analysis. Notes taken during the focus groups were also used as a data source.

\section{Analysis}

Qualitative content analysis served to generate themes and classify the responses into categories. The frequency of recurrence of each theme was taken into account. These categories were compared to potential categories drawn from a literature review. To categorize and structure the analysis, we followed the steps proposed by Guba and Lincoln for a constructivist evaluation..$^{10}$ Qualitative data from the interviews and focus groups were coded using NVivo 7 software (QSR International, Melbourne, Australia). ${ }^{11}$ In order to ensure the validity of the results, data were triangulated by two research assistants and verified randomly by the researchers.

\section{Results}

The clinicians chosen for the focus groups (four from the UHC, ten from the RC) represented several disciplines, including occupational therapy, physiotherapy, social work, neuropsychology, nursing, and medicine. Six administrators were interviewed individually, three from each institution.

In total, there were 68 patients with recruitment potential, but only 27 met the study criteria. Of those, 12 patients agreed to participate in the study, though only eleven completed both interviews. Figure 1 provides a summary of recruitment efforts and reasons for exclusion from the study.

Characteristics of PTBI participants $(\mathrm{n}=11,63.6 \%)$ were men aged $40.7 \pm 18.3$ years, a little over half of whom had suffered a severe TBI. Road accidents were the most common cause for the injury. Nine patients had a caregiver aged 23-70 years (average 50.7 years) that agreed to participate in the study. Most of the caregivers were women (88.9\%), and $45.5 \%$ were a parent of the patient. Please see Table 1.

\section{Qualitative results of the interviews and focus groups}

Themes identified in the interviews and focus groups are presented in the following sections.

\section{Theme I: Organization of care and services}

When asked about the organization of care and services, administrators and clinicians at the UHC described the different procedures required when a PTBI is admitted to the hospital. These include preadmission, reception, admission decision, and referral to the trauma team. Administrators and clinicians from both institutions also discussed patient management, which is carried out through assessments, team meetings, and meetings with patients and their caregivers. Decisions were made by the teams without necessarily involving the patients and their families. The patient's transfer from the UHC to the RC 


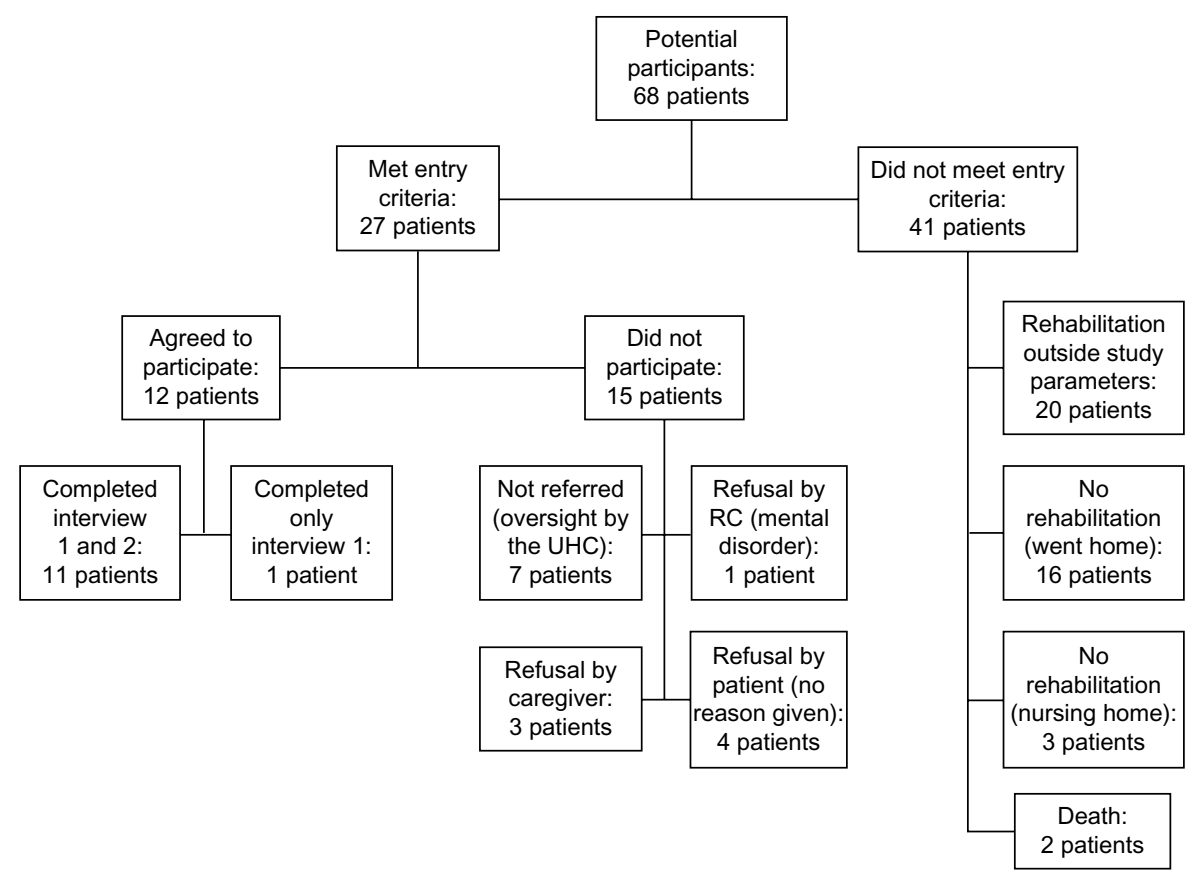

Figure I Recruitment flowchart.

Abbreviations: UHC, university hospital center; RC, rehabilitation center.

was crucial for the organization of care and services; one administrator reported:

We all have the same goal, to make the transfer in the best possible conditions. As quickly as possible. . .

(Administrator 2)

For the clinicians, patient management was done through evaluation and follow-up, intervening to inform the patient of how his condition was evolving.

For patients and their caregivers, the organization of care and services was discussed in terms of operations, follow-ups,

Table I Characteristics of participating patients with traumatic brain injury (TBI)

\begin{tabular}{ll}
\hline Patient characteristics $(\mathbf{n}=\mathbf{I} \mathbf{I})$ & \\
TBI severity, $\mathrm{n}(\%)$ & $5(45.5)$ \\
Moderate & $6(54.5)$ \\
Severe & \\
Type of accident, $\mathrm{n}(\%)$ & $4(36.4)$ \\
Car & $3(27.3)$ \\
Motorcycle & $\mathrm{I}(9.1)$ \\
Pedestrian & $2(18.2)$ \\
Fall & $\mathrm{I}(9.1)$ \\
Other & \\
Relationship to caregiver, $\mathrm{n}(\%)$ & $5(45.5)$ \\
Parent & $\mathrm{I}(9.1)$ \\
Brother/sister & $\mathrm{I}(9.1)$ \\
Son/daughter & $\mathrm{I}(9 . \mathrm{I})$ \\
Husband/spouse & $\mathrm{I}(9 . \mathrm{I})$ \\
Friend &
\end{tabular}

and treatment received. They often spoke about the discharge and transfer, which sometimes happened a bit too quickly. As one caregiver said:

We didn't really think he was getting out. He got out Wednesday - in fact, we found out at noon on Wednesday - but we thought he was getting out at the beginning of the week after. He was very happy when he learned he was getting out, but it really put us off balance. (Caregiver 8)

In summary, while the clinicians wanted to transfer patients as quickly as possible from the $\mathrm{UHC}$ to the $\mathrm{RC}$, their families were not always prepared for the transfer or given adequate advanced notice.

\section{Theme 2: Needs and expectations}

Clinicians and administrators emphasized that patient expectations, like the interventions, were primarily focused on enabling the patient to regain his or her autonomy. To accomplish this, clinicians had to understand the patient's circumstances and lifestyle:

... sometimes we manage . . . to get a certain amount of information on who the person was, where he came from, so that interventions can be put on track to restore the person's autonomy to what it was before the accident. (Clinician from group 2) 
From the point of view of patients and caregivers, the main expectation was for a return to autonomy, ie, to the patient's state before the accident:

So I work with all the clinicians to be able to put everything together so I can recover the life I had before. (Patient 1)

Our goals, of course we wanted her to become as much as possible like she was before. (Caregiver 5)

Clinicians and administrators saw patients and caregivers as having a range of needs. For patients, they could be physical (care, rest, walking), psychological (to calm down, be reassured), and social (presence, monitoring). The needs of caregivers were seen as psychological (to be informed, supported) and social (financial):

One way of identifying needs, of course when we talk as a team, we talk about the patient's needs, his handicap. Of course when we talk about needs, I know that anyone with a TBI has physical needs, I tend to look beyond that; it's so obvious I don't even talk about it. The patient needs to be followed. (Administrator 1)

I was saying that for the caregivers' needs, what we can see pretty easily here is that they need to be reassured, because their loved one could still have permanent damage, so that's the first level of need. The second is they need information, not just information when something happens; they need to know how things are evolving with our patient, their loved one. (Administrator 5)

In most cases, both the patients and the caregivers reported that all their needs were met:

I ask my nurses questions. When they don't know the answer, they go higher up and find out. I always, always get answers for what I need. (Patient 2)

Interviewer: When you say that you or your loved one get good care and services, what do you mean?

Well, looking after his physical needs, grooming, and medical needs. For myself, it's answering my questions. (Caregiver 3)

In our analysis of the qualitative data, we found that the clinicians were focused on the patients' needs, which were to regain a similar degree of autonomy to what they had before their accident. They were also aware that the families wanted to contribute.

\section{Theme 3: Participation of stakeholders in terms of involvement and responsibilities}

Administrators and clinicians described their respective roles and tasks as defined by their discipline. The PTBI said their role was to take time to rehabilitate and to follow their clinicians' recommendations. As for the caregivers, their tasks as participants in the care process were to look after the patient and inform clinicians of any change (or lack of change) in the patient's condition:

They were the ones [the clinicians] actually doing the work; they told me what to do. It was up to me to go the rest of the way to succeed. (Patient 8)

My responsibility now is to provide transportation for my daughter when she needs services. But apart from that, I wasn't asked to do anything, except for the coordinator's assessment, where I had to be present and give my perception of how I see my daughter now, and what sort of girl she was before the accident. That's been my only involvement. (Caregiver 1)

In all the interviews, we found that two stakeholders were actively involved with the patient and the patient's family. Clinicians have disciplinary involvement, one to one with the patient or family, but there was no evidence of interdisciplinary collaboration in patient-centered group meetings or rehabilitation plans involving all stakeholders with reference to the patient's or family's needs, having the patient or the caregiver present as a decision maker. The perception of the intervention team was that interprofessional intervention between sites did not occur.

\section{Theme 4: Perception of care continuity by all stakeholders}

According to the administrators and clinicians, the clinical care pathways to assure continuity of care worked out for $\mathrm{CC}$ were little used and needed to be reviewed because the process was too unwieldy. Nevertheless, they reported that CC contributed to better communication, helped avoid repeating assessments, gave fluidity and coordination to services between the two institutions, and fostered a change in ways of thinking. One thing they were especially proud of was the reduction in waiting times for patients to be transferred from the UHC to the $\mathrm{RC}$. The average waiting time fell from 15-20 days to 0-2 days.

Any category, whether it was a patient with a stroke or a PTBI, the wait times for transfer, I don't have it by heart, I had the sheet close by, it was about 20 days before the person left. At some point, we reduced it to a few days, no I didn't print it out. We reduced it to 6, 7 days. And now, within 24, 48 hours [the person is transferred]. Occasionally, there's a delay when the RC is overloaded. But generally, we're pretty much down to zero wait time. (Administrator 3) 
Both administrators and clinicians observed that after CC was implemented, patients and their caregivers were better prepared and better informed, and caregivers were given a bigger role:

So I think that in terms of $\mathrm{CC}$, as we try to increase transfer fluidity and make sure that people have as much information as possible, I think that can have an impact on the family. ... (Administrator 5)

It was a way to get the family involved. Plus, we give them a pamphlet. We tell them what's going to happen. They're given a form, we tell them what's going to happen. We put them in contact with the RC. That gets them more involved in the treatment. (Administrator 2)

Most of the patients and their caregivers noticed that there was no waiting period before the transfer from the UHC to the $\mathrm{RC}$, and felt there was good coordination and continuity of care from one institution to the other. It is important to note that all stakeholders agreed that the patients received good care, at the right time, from the right person, and in the right place.

So whether it's within an organization or between organizations, you have to care about making sure the client has the right services at the right time from the right teams. ... (Administrator 4)

\section{Theme 5: Degree of satisfaction with the care process}

Administrators and clinicians were satisfied with the new approach to organizing care and services, and felt supported by their colleagues and superiors. Small irritants were brought up, however, including use of the computer system and the absence of specialists involved in patient care from UHC team meetings. Also, as described by one participant:

The purpose of $\mathrm{CC}$, in a way, was to put all of us on the same level, and above all to make the UHC work like a sort of relay race instead of an obstacle race. (Clinician from group 2)

Regarding most of the care and services received, the patients and caregivers were highly satisfied, going so far as to rate them ten out of ten. There was some dissatisfaction with elements externals to $\mathrm{CC}$, such as the quality of meals, difficulties with the nursing staff, and the unavailability of some physicians in private clinics. It should be noted that one caregiver reported that the timetable for meetings with $\mathrm{RC}$ clinicians conflicted with his job. Another hinted that physicians at the RC were not always available.

\section{Suggestions and improvements}

Administrators and clinicians suggested revising the clinical pathways, meeting more frequently with patients and especially caregivers, eliminating the step of going through the physiatrist for discharge from the UHC (redundant, stretches out the hospital stay), involving nursing staff more, and extending $\mathrm{CC}$ to other clienteles. Therefore, there are still improvements to be made in patient transfer and teamwork.

For patients and caregivers, it is important to improve the organization of care and services generally, and to have better access to care and physicians. It is also important to improve relational aspects like communication, listening, information, and support.

\section{Discussion}

The purpose of this study was to describe the implementation of CC and to provide a perception of the quality of care and services for TBI patients. The $\mathrm{CC}$ approach requires that every stakeholder be involved with every care episode. As noted by Cope et al, optimal rehabilitation of PTBI requires coordination between the acute care provided in hospitals and the type of care offered in rehabilitation centres. ${ }^{12}$ The $\mathrm{CC}$ approach was designed to bridge the gap between institutions that provide care to PTBI and optimizing rehabilitation by reducing the transfer time. Reducing the transfer time to 1 day is a sign of efficient care.

The themes covered in the interviews were also comparable to the literature. All of the actors we met placed special attention on the process of patient transfer between the two institutions. This period, pivotal for rehabilitation, was hard on the patient's loved ones. A qualitative study of head trauma patients, their families, and the professionals involved in their care has shown that the switch from hospital care to rehabilitative care is destabilizing, because the new environment is less structured and thus more stressful for both patient and family. ${ }^{13}$

The stakeholders also agreed that the implicit goal of the patient's rehabilitation was the recovery of their autonomy prior to the accident. This agrees fully with a qualitative study on evaluating the needs of patients with a head trauma and their families, which showed that patients express a need to be prepared and given the skills required for a return home and in the community. ${ }^{14}$ The purpose of rehabilitation is to help the person regain, as much as possible, the level of functioning they had before the accident. ${ }^{15,16}$

Both institutions in our study focused on a patient's physical needs with regard to improving their state of health. Few studies have looked at the needs of PTBI during 
hospitalization, despite findings that change depends on the circumstances of the rehabilitation process. ${ }^{14}$ As for the needs of caregivers, they were like those in studies published in the literature on the needs of families with a relative in critical care. ${ }^{17-23}$ These articles demonstrate the importance placed by families on being informed of the loved one's state of health.

Of greater significance regarding the theme of participation is the role of the PTBI and their caregiver. Patients had to make an effort to achieve their rehabilitation, and caregivers wanted to participate in providing care and supporting the patient throughout this process. A study on the needs of families of patients with severe head trauma showed that family members wanted to participate actively in the patient's care, with some even feeling frustrated when they could not help. ${ }^{19}$ Yet only $15 \%$ of caregivers in another study were really involved in decisions on their loved one's care. ${ }^{24}$

When CC was being implemented, clinical pathways were proposed as a tool for communication among professionals. The tool was not regularly used, because it did not have standardized indicators. Nevertheless, the use of such a tool did facilitate the patient's progress and communication among the various clinicians. ${ }^{25}$

Implementing the $\mathrm{CC}$ approach has been found to have several benefits, including improved communication, greater continuity of care, coordination of services between institutions, and better preparation, awareness and involvement of patients and their families. This patient-centered approach has resulted in significant changes, similar to those reported in the literature. ${ }^{26}$ In the present study, introducing CC reduced the waiting time for patient transfer from the hospital to the rehabilitation center, from 10 to 1 day's waiting time. Similarly, the study on the CC model in three independent hospitals showed a reduction in both the length of stay and costs per admission. ${ }^{27}$ Transferring a patient more quickly to a rehabilitation center has a positive impact on the time required for the rehabilitation of patients with severe trauma. ${ }^{28}$ On the whole, patients and their caregivers were satisfied with the care received, a fact established in studies on the satisfaction levels of patients and their families..$^{29,30}$

There are limitations in our study, including the small number of patients available for recruitment. This can be explained by a regional reorganization of patient distribution that took place during the study period, resulting in fewer patients being sent to the institutions included in the study. In addition to this, a number of patients in our target population received rehabilitation care outside the region and were thus not included in our study.

\section{Conclusion}

The implementation of the CC approach at our institution yielded favorable results in terms of the quality of care and services provided to PTBI, as perceived by the patients themselves, their caregivers, clinicians, and hospital administrators. Patients reported being satisfied with the care and services they received, while clinicians and administrators reported improvements in transfer times between institutions as well as better coordination of care between the hospital and rehabilitation center.

\section{Acknowledgments}

The authors wish to thank the Fonds de recherche Québécois en santé for its financial support, and the patients, caregivers, clinicians, and administrators for their time and wise suggestions. Many thanks to Jennifer Chambers for her excellent suggestions during the scientific review.

\section{Disclosure}

The authors report no conflicts of interest in this work.

\section{References}

1. Canadian Institute for Health Information (CIHI). National Trauma Registry Report 2013: Hospitalization for a Major Injury in Canada, 2010-2011 Data. Ottawa: CIHI; 2013.

2. Regroupement des Associations de Personnes Traumatisées Craniocérébrales du Québec. Le TCC, c'est quoi? [Traumatic brain injury association of Québec. What is brain injury?]. 2013. Available from: http://www.raptccq.com/fr/raptccq/le-tcc-cest-quoi.html. Accessed January 13, 2012. French.

3. McGarry LJ, Thompson D, Millham FH, et al. Outcomes and costs of acute treatment of traumatic brain injury. $J$ Trauma. 2002;53: $1152-1159$

4. Lefebvre H, Pelchat D, Héroux M. Partenariat familles, professionnels, gestionnaires: vers une continuité de soins et services [Family, professionals and managers partnership: towards continuity of care and services]. Ruptures (Univ Montr Groupe Rech Interdiscip Sante). 2003;9:127-146. French.

5. Cohen JJ. Collaborative care: a new model for a new century. $J$ Med Educ. 2000;75:107-112.

6. Régie Régionale de la Santé et des Services Sociaux Estrie. Direction de la Santé Publique et de l'Evaluation [Regional center for Health and social services in Eastern Townships, Direction of Public Health]. 2001. French.

7. Zander K. Managing Outcomes Through Collaborative Care: The Application of Caremapping and Case Management. Chicago: American Hospital Association; 1995.

8. Donabedian A. The quality of care. How can it be assessed? JAMA. 1988;260:1743-1748.

9. Morgan DL, Krueger RA. Analysing and Reporting Focus Group Results (Focus Group Kit). London: Sage; 1998.

10. Guba EG, Lincoln YS. Fourth Generation Evaluation. Newbury Park (CA): Sage; 1989.

11. QSR International. NVivo qualitative data analysis software. Version 7. Melbourne: QSR; 2006.

12. Cope DN, Mayer NH, Cervelli L. Development of systems of care for persons with traumatic brain injury. J Head Trauma Rehabil. 2005;20:128-142. 
13. Lefebvre H, Pelchat D, Swaine B, Gélinas I, Levert MJ. The experiences of individuals with a traumatic brain injury, families, physicians and health professionals regarding care provided throughout the continuum. Brain Injury. 2005;19:585-597.

14. Rotondi AJ, Sinkule J, Balzer K, Harris J, Moldovan R. A qualitative needs assessment of persons who have experienced traumatic brain injury and their primary family caregivers. J Head Trauma Rehabil. 2007;22:14-25.

15. Chua KSG, Ng YS, Yap SM, Bok C. A brief review of traumatic brain injury rehabilitation. Ann Acad Med Singapore. 2007;36:31-42.

16. Khan F, Baguley IJ, Cameron ID. Rehabilitation after traumatic brain injury. Med J Aust. 2003;178:290-295.

17. Alvarez GF, Kirby AS. The perspective of families of the critically ill patient: their needs. Curr Opin Crit Care. 2006;12:614-618.

18. Auerbach SM, Kiesler DJ, Wartella J, Rausch S, Ward KR, Ivatury R. Optimism, satisfaction with needs met, interpersonal perceptions of the healthcare team, and emotional distress in patients' family members during critical care hospitalization. Am J Crit Care. 2005;14: 202-210.

19. Bond E, Draeger CR, Mandleco B, Donnelly M. Needs of family members of patients with severe traumatic brain injury: implications for evidence-based practice. Crit Care Nurs. 2003;23:63-72.

20. O'Callaghan AM, McAllister L, Wilson L. Experiences of care: perspectives of carers of adults with traumatic brain injury. Int J Speech Lang Pathol. 2011;13:218-226.

21. Sinnakaruppan I, Williams DM. Family carers and the adult head-injured: a critical review of carers' needs. Brain Injury. 2001;15:653-672.
22. Stebbins P, Leung P. Changing family needs after brain injury. J Rehabil. 1998;4:15-22.

23. Van der Merwe J. Family Needs Following Adult Traumatic Brain Injury [master's thesis]. Port Elizabeth, South Africa: University of Port Elizabeth; 2004.

24. Azoulay E, Pochard F, Chevret S, et al. Half the family members of intensive care unit patients do not want to share in the decision-making process: a study in 78 French intensive care units. Crit Care Med. 2004;32:1832-1838.

25. Vitaz TW, McIlvoy L, Raque GH, Spain D, Shields CB. Development and implementation of a clinical pathway for severe traumatic brain injury. J Trauma. 2001;51:369-375.

26. Bergeson SC, Dean JD. A systems approach to patient-centered care. JAMA. 2006;296:2848-2851.

27. McKay CA, Crippen L. Collaboration through clinical integration. Nurs Admin Q. 2008;32:109-116.

28. Sirois M, Lavoie A, Dionne CE. Impact of transfer delays to rehabilitation in patients with severe trauma. Arch Phys Med Rehabil. 2004;85: 184-191.

29. Henrich NJ, Dodek P, Heyland D, et al. Qualitative analysis of an intensive care unit family satisfaction survey. Crit Care Med. 2011;39: $1000-1005$.

30. Heyland DK, Rocker GM, Dodek PM, et al. Family satisfaction with care in the intensive care unit: results of a multiple center study. Crit Care Med. 2002;30:1413-1418.
Journal of Multidisciplinary Healthcare

\section{Publish your work in this journal}

The Journal of Multidisciplinary Healthcare is an international, peerreviewed open-access journal that aims to represent and publish research in healthcare areas delivered by practitioners of different disciplines. This includes studies and reviews conducted by multidisciplinary teams as well as research which evaluates the results or conduct of such teams or

\section{Dovepress}

healthcare processes in general. The journal covers a wide range of areas and welcomes submission from practitioners at all levels, from all over the world. The manuscript management system is completely online and includes a very quick and fair peer-review system. Visit http://www.dovepress.com/testimonials.php to read real quotes from published authors. 